\title{
NOŚNOŚĆ ZAKOTWIENIA STALOWEGO MASZTU ANTENOWEGO W ISTNIEJĄCYCH ELEMENTACH BUDYNKU
}

\begin{abstract}
$\mathrm{W}$ artykule przedstawiono problematykę połączenia - zakotwienia stalowego masztu antenowego w istniejących elementach żelbetowych budynku takich jak stropodach czy ściana. W procesie projektowania zakotwienia należy sprawdzić wiele warunków nośności takich jak nośność na zerwanie stali, na zniszczenie przez wyrywanie betonu czy na ścinanie łączników. Połączenie źle zaprojektowane może doprowadzić tym samym do awarii lub katastrofy, co będzie z sobą niosło uszkodzenia zarówno samej konstrukcji masztu, elementów wyposażenia, jak i elementów obiektu, na którym ta konstrukcja jest stawiana.
\end{abstract}

Słowa kluczowe: kotwy stalowe, wyrywanie, ścinanie, zniszczenie stali, rozłupanie betonu.

\section{Charakterystyka stalowych lączników kotwiących}

Intensywny rozwój telefonii komórkowych stwarza potrzebę zapewnienia zasięgu, który ma sprostać wymaganiom klientów. Co za tym idzie, należy stawiać nowe nadajniki anten, umieszczone na masztach [5]. Budowle te, stawiane w dalekiej odległości od siedlisk miejskich, nie dawały wystarczającego zasięgu. Tym samym zaczęto szukać nowych możliwości poprawy tej sytuacji maszty antenowe zaczęto stawiać na istniejących budynkach czy budowlach takich jak kominy czy silosy. Sposób ten stał się lepszym rozwiązaniem pod względem ekonomicznym oraz technologicznym: montaż masztów na istniejących obiektach budowlanych jest tańszy niż stawianie samodzielnego masztu, co nie zawsze jest możliwe ze względu na planowanie przestrzenne miast oraz daje lepszy zasięg działania nadajników antenowych.

\footnotetext{
${ }^{1}$ Anna Kucharczyk, mgr inż., Uniwersytet Zielonogórski, ul. Prof. Z. Szafrana 1, 65 - 516 Zielona Góra, tel.: (0 68) 32878 03, A.Kucharczyk@ib.uz.zgora.pl
} 

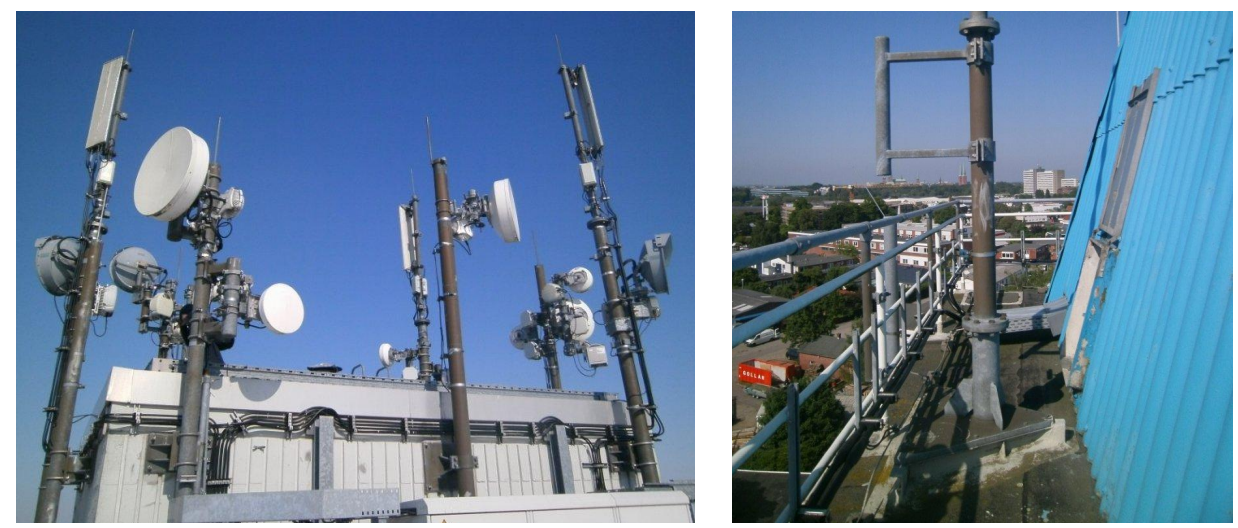

Rys. 1. Sposoby montowania masztu na istniejących obiektach: lewa strona - do ściany, prawa strona - do stropodachu.

Fig. 1. Methods of mounting mast on existing facilities: the left side - on the wall, right side - the flat roof.

Maszty montowane są do istniejących elementów obiektów budowlanych (stropodachów, więźb dachowych, ścian, trzonów kominów itp. - rys. 1) za pomocą stalowych łączników kotwiących. Jest to jedyne połączenie konstrukcji masztowej z istniejącym obiektem.

Na rynku można spotkać bardzo wiele rodzajów i producentów tych łączników. Na rys. 2 przedstawiono najczęściej spotykane rodzaje kotwi [9].

a)

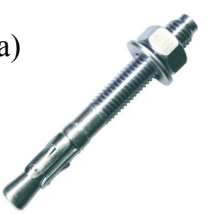

b)

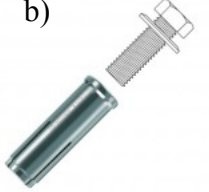

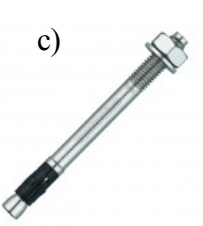

d)

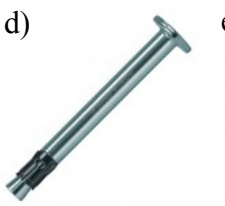

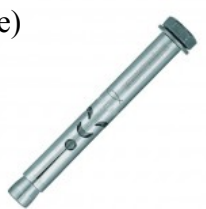

Rys. 2. Rodzaje łączników kotwiących: a) dybel stalowy wkręcany, b) kotwa wbijana, c) kotwa sworzniowa, d) kotwa gwoździowa, e) kotwa tulejowa Źródło: www.fischerpolska.pl

Fig. 2. Types of anchors: a) steel wedge anchor, b) hammered anchor, c) bolted anchor, d) nailed anchor, e) sleeved anchor. Source: www.fischerpolska.pl

Stalowe łączniki kotwiące można używać przy mocowaniu do elementów betonowych niezarysowanych, według zaleceń producenta [9] i [10], o klasie betonu większej niż C20/25. 


\section{Algorytm wyznaczania nośność połączenia zakotwienia masz- tu według metody A}

\subsection{Reakcje w węźle}

Aby wyznaczyć nośność połączenia zakotwienia masztu w istniejącym elemencie konstrukcyjnym obiektu budowlanego należy znać reakcje, uwzględniające częściowy współczynnik bezpieczeństwa, podane w [1], [4] i [8], dla zadanych obciążeń, w węźle bądź w węzłach kotwiących budowlę masztową. Należy znać:

- obciążenie wyrywające $N_{S d}$;

- $\quad$ siłę ścinającą w kierunku osi poziomych x i y - $V_{S d, x}$ i $V_{S d, y}$;

- moment zginający wokół osi poziomych x i y - $M_{S d, x}$ i $M_{S d, y}$;

- moment skrętny wokół osi pionowej z $-M_{T, S d}$.

Następnym krokiem jest podanie wynikowych sił na kotwy oraz wyznaczenie $\mathrm{w}$ przekroju betonowych zasięgu strefy ściskanej i rozciąganej według [3].

\subsection{Nośność obliczeniowa na wyrywanie}

Nośność obliczeniowa łączników kotwiących na wyrywanie składa się z wyznaczenia dla najbardziej niekorzystnie obciążonej kotwi według [10]:

- zniszczenia (zerwania) stali;

- zniszczenia poprzez wyrywanie stożka betonowego;

- zniszczenia poprzez rozłupanie betonu przy obciążeniu.

Nośność na zniszczenie (zerwanie) stali sprawdza się z warunku:

$$
N_{S d} \leq \frac{N_{R k, \mathrm{~s}}}{\gamma M_{s}}=N_{R d, s}
$$

gdzie: $N_{S d}$ - siła wyrywająca,

$N_{R k, s}$ - nośność charakterystyczna kotwi na zniszczenie / zerwanie stali,

$N_{R d, s}$ - nośność obliczeniowa kotwi na zniszczenie / zerwanie stali,

$\gamma M_{s}$ - współczynnik częściowy bezpieczeństwa dla zniszczenia stali.

Nośność najbardziej obciążonego łącznika zależy od jego pola powierzchni $A_{s}$ oraz od wytrzymałości charakterystycznej na rozciąganie $f_{u k}$ :

$$
N_{R k, s}=A_{s} \cdot f_{u k}
$$


Nośność na zniszczenie poprzez wyrywanie stożka betonowego sprawdza się z warunku:

$$
N_{S d} \leq \frac{N_{R k, c}}{\gamma M_{c}}=N_{R d, c}
$$

gdzie: $N_{R k, c}$ - wartość charakterystyczna nośności łącznika na zniszczenie poprzez wyrywanie stożka betonowego,

$\gamma M_{c}$ - współczynnik częściowy bezpieczeństwa dla zniszczenia betonu,

$N_{R d, c}$ - wartość obliczeniowa nośności łącznika na zniszczenie poprzez wyrywanie stożka betonowego.

Wartość charakterystyczną nośności łącznika na zniszczenia wyznacza się ze wzoru:

$$
N_{R k, c}=N_{R k, c}^{0} \cdot \frac{A_{c, N}}{A_{c, N}^{0}} \cdot \psi_{s, N} \cdot \psi_{r e, N} \cdot \psi_{c c, N}
$$

$\mathrm{Na}$ nośność charakterystyczną kotwi na zniszczenie bądź zerwanie ma wpływ stosunek powierzchni betonu wokół łącznika kotwiącego, którego odległość do krawędzi, idealizując powierzchnię do stożka betonowego jako piramidy o wysokości równej głębokości zakotwienia $h_{e f}$ i długości podstawy równej $s_{c r, N}$ (rys. 2) do rzeczywistej powierzchni betonu ograniczonej przez nakładające się stożki sąsiednich łączników (rys. 3).

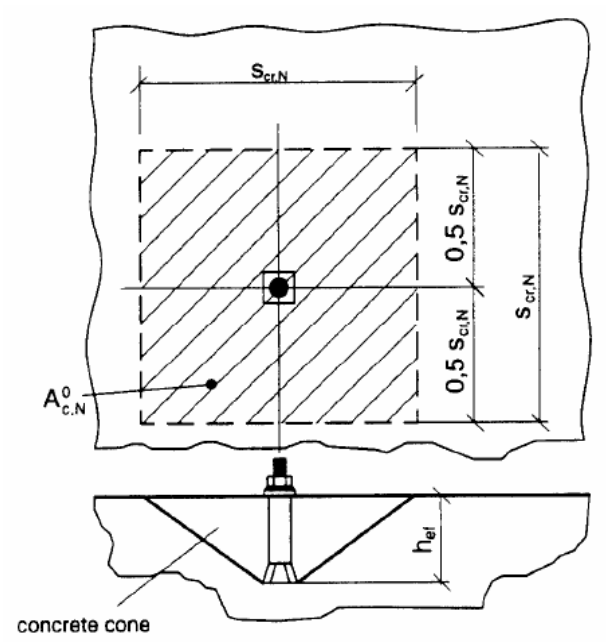

Rys. 3. Wyidealizowany betonowy stożek i powierzchnia $A_{c, N}$ dla pojedynczego łącznika.

Fig. 3. Idealized concrete cone and area $A_{c, N}$ of concrete cone of an individual anchor. 
a)

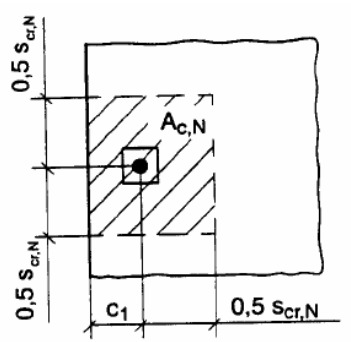

b)

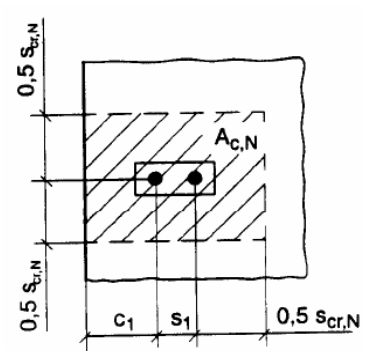

c)

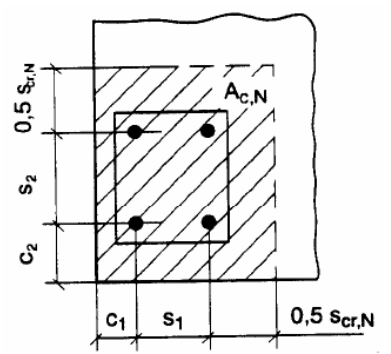

Rys. 4. Przykłady rzeczywistej powierzchni betonu $A_{c, N}$ dla różnych rozmieszczeń łączników w przypadku działania obciążenia rozciąganego osiowo dla a) pojedynczego łącznika, b) grupy dwóch łączników, c) grupy czterech łączników na krawędzi betonowego elementu.

Fig. 4. Examples of actual areas $A_{c, N}$ of the idealized concrete cones for different arrangements of anchors in the case of axial tension load a) individual anchor, b) group of two anchors, c) group of four anchors at the edge of concrete element.

Wpływ na końcową wartość nośności na zniszczenie / zerwanie stali ma również początkowa wartość nośności charakterystycznej kotwi umieszczonej w zarysowanym lub niezarysowanym betonie:

$$
N_{R k, c}^{0}=k_{1} \cdot \sqrt{f_{c, c u b e}} \cdot h_{e f}^{1.5}
$$

gdzie: $k_{1}$ - współczynnik: dla betonu niezarysowanego przyjmuje się 10,1; dla betonu zarysowanego 7,2.

$f_{c, \text { cube }}$ - wytrzymałość betonowej próbki sześciennej na ściskanie, $h_{e f}-$ głębokość zakotwienia łącznika (rys. 3).

oraz współczynniki:

a) $\psi_{s, N}$ - uwzględniający zaburzony rozkład naprężeń na krawędzi betonu. Dla zamocowań brzegowych na kilku odcinkach, np. zakotwienie na narożniku betonowego elementu lub do wąskiego elementu zależy to od minimalnej grubości otuliny $c$ :

$$
\psi_{s, N}=\min \left(1 ; 0,7+0,3 \cdot \frac{c}{c_{c r, N}}\right) \leq 1,0
$$

b) $\psi_{r e, N}$ - uwzględniający kruszenie się powłoki betonu i efekt wzmocnienia:

$$
\psi_{\mathrm{re}, N}=0.5+\frac{h_{e f}}{200} \leq 1,0
$$


Współczynnik ten przyjmuje wartość równą 1,0 bez względu na głębokość zakotwienia łącznika, jeżeli w obszarze kotwienia jest zbrojenie o dowolnej średnicy w rozstawie większym niż $150 \mathrm{~mm}$ lub o średnicy mniejszej niż $10 \mathrm{~mm}$ i rozstawie większym niż $100 \mathrm{~mm}$.

c) $\psi_{e c, N}-$ uwzględniający efekt działania grupy łączników, w sytuacji gdy rózne naprężenia od obciążeń działają na pojedyncze kotwy z grupy:

$$
\psi_{\mathrm{ec}, N}=\frac{1}{1+\frac{2 e_{N}}{s_{c r, N}}} \leq 1,0
$$

gdzie: $e_{N}{ }^{-}$mimośród obciążenia mającego wpływ na rozciąganie kotew.

Jeżeli mimośród działa $\mathrm{w}$ obu kierunkach poziomych, współczynnik $\psi_{e c, N}$ powinno się ustalać osobno dla każdego kierunku, a wynik obu współczynników umieszcza się w równaniu (4).

Nośność na zniszczenie poprzez rozłupanie betonu przy obciążeniu można pominąć przy obliczeniach $\mathrm{w}$ trzech przypadkach:

1) jeżeli odległość do krawędzi $c$ we wszystkich kierunkach poziomych jest większa od odległości zapewniającej przekazanie charakterystycznej wytrzymałości na rozciąganie pojedynczej kotwi $c_{c r, s p}$;

2) grubość elementu betonowego jest większa od dwukrotności głębokości zakotwienia;

3) maksymalna szerokość rys jest mniejsza niż $0,3 \mathrm{~mm}$.

Jeżeli te warunki nie są spełnione, należy sprawdzić nośność betonu na zniszczenie poprzez rozłupanie przy obciążeniu wg wzoru:

$$
N_{R k, s p}=N_{R k, c p}^{0} \frac{A_{c, N}}{A_{c, N}^{0}} \cdot \psi_{s, N} \cdot \psi_{r e, N} \cdot \psi_{e c, N} \cdot \psi_{h, \mathrm{sp}}
$$

Składowe wzoru wyznacza się wg równań (5) - (8), z tą różnicą, że do wzorów podstawia się odpowiednio wartości charakterystyczne dla rozłupania betonu $c_{c r, s p}$ i $s_{c r, s p}$.

a) $\psi_{h, s p}$ - współczynnik uwzględniający wpływ rzeczywistej grubości elementu na odporność betonu na rozłupywanie dla kotew: 


$$
\psi_{h, \mathrm{sp}}=\left(\frac{h}{h_{\min }}\right)^{2 / 3} \leq 1,5
$$

gdzie: $h^{-}$rzeczywista grubość elementu,

$h_{\min }$ - grubość elementu, dla której zostało wyznaczone $c_{c r, s p}$,

$h_{\min } \leq 2 \mathrm{~h}_{\mathrm{ef}}$.

Jeżeli odległość kotwi od krawędzi jest mniejsza niż $c_{c r, s p}$, to krawędź elementu powinna być wzmocniona dodatkowym zbrojeniem podłużnym.

\subsection{Nośność kotwi na ścinanie}

Nośność kotwi na ścinanie wyznacza się za pomocą określenia:

- nośności na zniszczenie (zerwanie) stali bez zginania;

- nośności na odłupanie betonu po przeciwnej stronie do przyłożenia obciążania.

Nośność na zniszczenie (zerwanie) stali bez zginania wyznaczana jest w dwóch aspektach:

1) bez działania mechanizmu dźwigni - występuje na elementach łączonych przez zgrzewanie bądź nie przyspawanego do stalowego elementu - blachy. Obliczenia wytrzymałości są oparte na charakterystycznej wytrzymałości stali na rozciąganie oraz na polu przekroju poprzecznego kotwi:

$$
V_{R k, s}=A_{s} \cdot f_{u k}
$$

W przypadku grup kotwi charakterystyczna wartość nośności na ścinanie powinna być pomnożona przez współczynnik równy 0.8 , w sytuacji, gdy łącznik jest wykonany ze stali o stosunkowo niskiej ciągliwości (wydłużenie pęknięcia $<8 \%$ ). Równanie (11) nie dotyczy kotwi o mniejszym przekroju w stosunku do długości śruby, np. kotwie rozporowe.

2) w występującym działaniem mechanizmu dźwigni - w innych przypadkach niż te, wymienione w 1). Wyznacza się nośność ze wzoru:

$$
V_{R k, s}=\frac{\alpha_{M} \cdot M_{R k, s}}{\ell}
$$

gdzie: $\alpha_{M}$ - współczynnik, który zależy od stopnia naciągu kotwi od strony urządzenia montującego:

$\alpha_{M}=1,0$ dla kotwi bez naciągu;

$\alpha_{M}=2,0$ dla kotwi z pełnym naciągiem;

$M_{R k, s}$ - charakterystyczna nośność na zginanie,

$\ell$-ramię dźwigni 
Na charakterystyczną nośność na zginanie $M_{R k, s}$ ma wpływ stosunek siły zrywającej $N_{S d}$ do nośności obliczeniowej na zerwanie (zniszczenie) kotwi $N_{R d, s}$ oraz nośność charakterystyczna na zginanie pojedynczej kotwi $M_{R k, s}$ :

$$
M_{R k, s}=M_{R k, s}^{0} \cdot\left(1-\frac{N_{s d}}{N_{R d, s}}\right)
$$

Wartość nośności charakterystycznej pojedynczej kotwi na zginanie wyznacza się ze wzoru (14) w przypadku, gdy kotwa nie ma znacznie zmniejszonego przekroju w stosunku do długości.

$$
M_{R k, s}^{0}=1,2 \cdot W_{e l} \cdot f_{u k}
$$

gdzie: $W_{e l}$ - wskaźnik sprężystości przekroju.

Kotwienie może być również powodem odłupania betonu po przeciwnej stronie niż przyłożone obciążenie, wtedy należy wyznaczyć także nośność na odłupanie betonu po przeciwnej stronie do przyłożenia obciążania:

$$
V_{R k, c p}=k \cdot N_{R k, c}
$$

gdzie: $k$ - współczynnik zależny od głębokości kotwienia $h_{e f}$

$$
\mathrm{k}=1 \text {, gdy } \mathrm{h}_{\mathrm{ef}}<60 \mathrm{~mm}
$$

$\mathrm{k}=2$, gdy $\mathrm{h}_{\mathrm{ef}} \geq 60 \mathrm{~mm}$

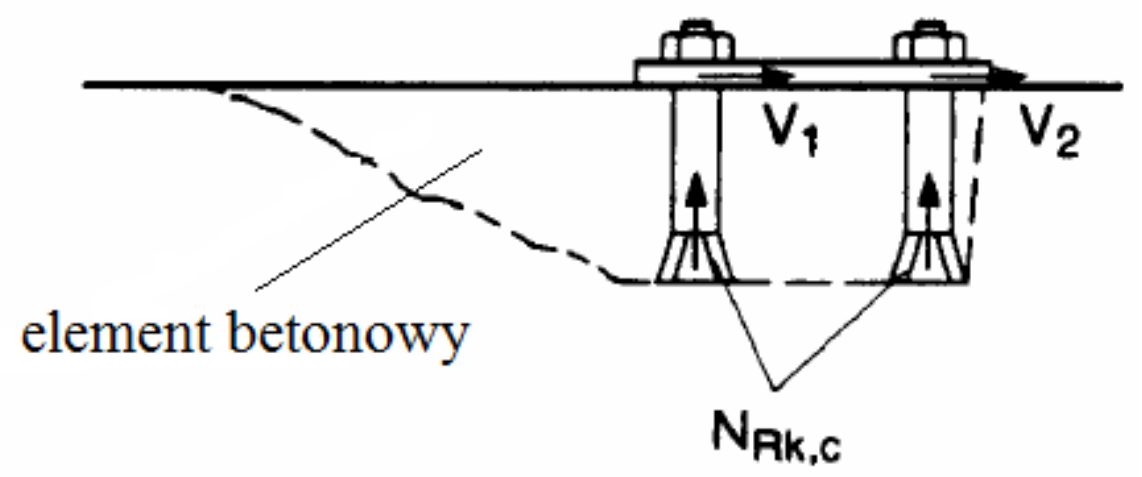

Rys. 5. Mechanizm zniszczenia betonu przez działanie siły po przeciwnej stronie przyłożenia obciążenia.

Fig. 5. Concrete pry-out failure on the side opposite to load direction. 
W przypadku sił ścinających lub/i momentów skrętnych działających na grupę kotwi kierunki obciążeń poprzecznych mogą się zmieniać, co pokazano na rys. 6.

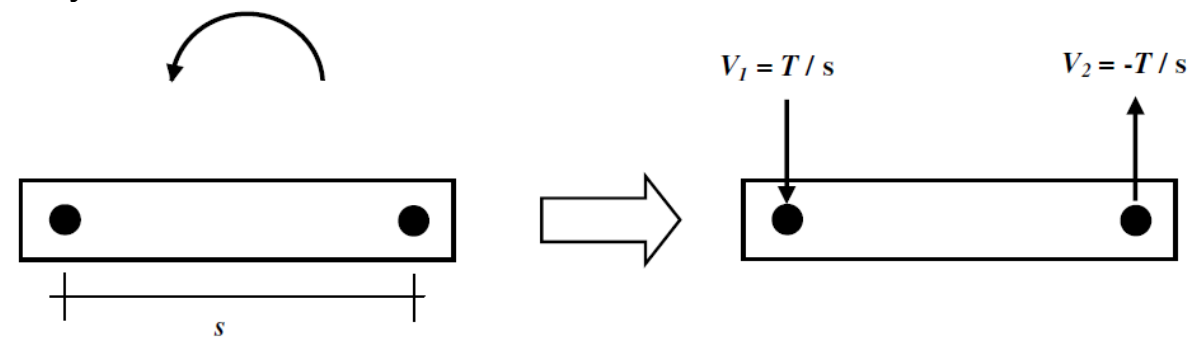

Rys. 6. Grupa kotew obciążona momentem skrętnym (lewa strona). Zmieniające swoje kierunki obciążenie ścinające działające na grupę kotwi (prawa strona).

Fig. 6. Group of anchors loaded by a torsion moment (left side). Shear loads acting on the individual anchors of the group alter their directions (right side).

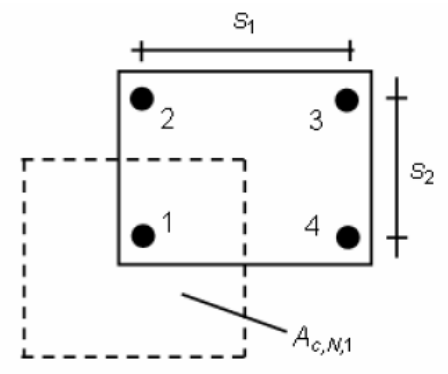

$$
\begin{aligned}
& A_{c, N, 1}=\left(0.5 \cdot s_{c r, N}+s_{1} / 2\right) \cdot\left(0.5 \cdot s_{c r, N}+s_{2} / 2\right) \\
& A_{c, N, 2}=A_{c, N, 1} \\
& A_{c, N, 3}=A_{c, N, 1} \\
& A_{c, N, 4}=A_{c, N, 1} \\
& \left(s_{1} ; s_{2}\right) \leq s_{c r, N}
\end{aligned}
$$

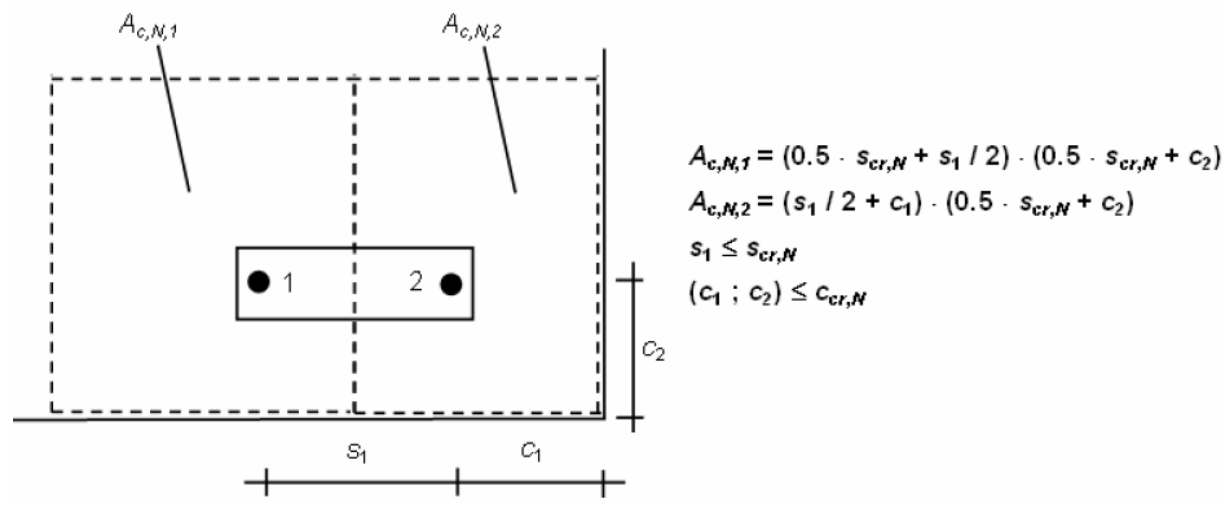

Rys. 7. Przykłady wyznaczenia pola $A_{c, N}$ dla betonowych stożków: góra - grupa czterech kotew, dół - grupa dwóch kotew zamocowanych w bliskości narożnika elementu.

Fig. 7. Examples for the calculation of the area $A c, N$ of the idealised concrete cones: up - group of four anchors, down - group of two anchors in a corner. 
W przypadkach, gdy poziome lub pionowe składowe obciążeń ścinających kotwie zmieniają swój kierunek weryfikowanie zniszczenia przez rozłupywanie betonu ogranicza się dla najbardziej obciążonej kotwi. Przy obliczaniu nośności wpływ ma zarówno odległość od krawędzi jak i rozstaw kotwi. Nośność kotwi na zerwanie uwzględniona przy wyznaczeniu nośności na odłupanie betonu wyznacza się analogicznie z równania (4), zmieniając przy tym pola powierzchni $A_{c, N}$ jak na rys. 7.

\section{Wnioski końcowe i podsumowanie}

Zakotwienie masztu $\mathrm{w}$ istniejącym elemencie konstrukcyjnym budynku jest newralgicznym punktem wymiarowania, ponieważ stanowi jedyne połączenie konstrukcji masztu $\mathrm{z}$ obiektem, na którym jest wznoszone. Poprawnie zaprojektowane połączenie powinno oznaczać się wytężeniem $\mathrm{z}$ uwzględnieniem wyrywania i ścinania $w$ granicach 55\% [9]. Istniejące podłoże betonowe powinno spełniać warunki nośności na ścinanie i wyrywanie, stan powinien być sprawdzony i potwierdzony ekspertyzą budowlaną. W innym przypadku należałoby wzmocnić sama konstrukcję podłoża poprzez dołożenie prętów zbrojeniowych w obrębie montowanego masztu.

W przeciwnym razie, złe podłoże oraz błędy w wymiarowaniu połączenia zakotwienia może doprowadzić do katastrofy budowlanej, co opisano w [7].

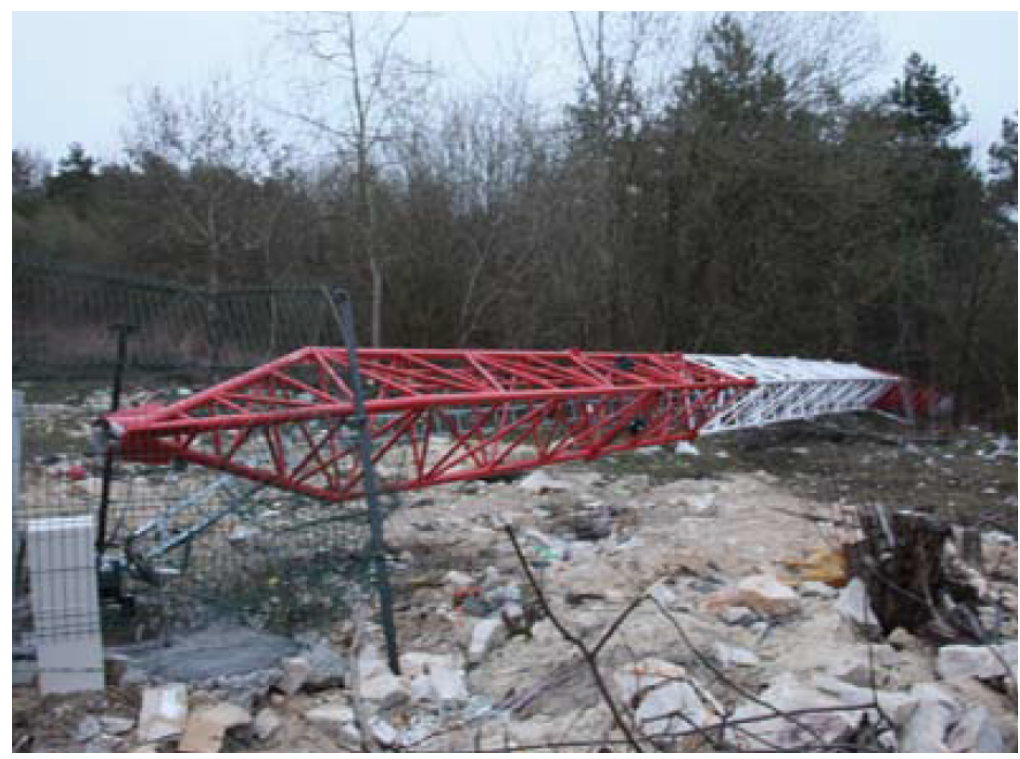

Rys. 8. Awaria aluminiowego masztu antenowego o wysokości 80,00m. Źródło: www.inzynierbudownictwa.pl

Fig. 8. Failure aluminum mast with a height of $80,00 \mathrm{~m}$. Source: www.inzynierbudownictwa.pl 


\title{
Literatura
}

[1] PN-EN 1990 Eurokod Podstawy projektowania konstrukcji.

[2] PN-EN 1991-1-4 Eurokod 1: Oddziaływania na konstrukcje. Część 1-4: Oddziaływania ogólne. Oddziaływania wiatru.

[3] PN-EN 1992-1-1 Eurokod 2: Projektowanie konstrukcji z betonu. Część 1 - 1: Reguły ogólne i reguły dla budynków.

[4] PN-EN 1993-1-1 Eurokod 3: Projektowanie konstrukcji stalowych. Część 1-1: Reguły ogólne i reguły dla budynków.

[5] PN-EN 1993-3-1 Eurokod 3: Projektowanie konstrukcji stalowych. Część 3-1: Wieże, maszty i kominy. Wieże i maszty.

[6] Łubiński M., Żółtowski W.:Konstrukcje metalowe. Część II. Wyd. Arkady Warszawa 2004.

[7] Sendkowski J., Tkaczyk A., Tkaczył Ł.: Katastrofa budowlana aluminiowego masztu telekomunikacyjnego z odciągami, Inżynier budownictwa, $\mathrm{nr}$ 12, 2015, s. 104109.

[8] Matuszkiewicz M.: Obliczanie kratowych masztów z odciągami według PN-EN 1993-3-1, Inżynieria i Budownictwo, nr 4/2010, 2010, s. 589-593.

[9] Europejska Aprobata Techniczna ETA-05/0069 dla kotwi sworzniowych fischer FAZ II.

[10] Guideline for European technical approval of metal anchors for use in concrete ETAG 001, 2013.

\section{STRENGTH OF STEEL MAST ANCHORING IN THE EXISTING BUILDINGS ELEMENTS.}

\begin{abstract}
S u m m a r y
The article presents the problem of call - anchor steel antenna mast in existing reinforced concrete building elements such as flat roof or wall. In the process of designing anchoring check the capacity of many conditions such as load capacity of breaking steel, for destruction by pulling-out concrete or shear connectors. The connection of poorly designed may result in failure or disaster, what will become of them carried the damage of both the mast construction, equipment, as well as elements of the object on which the construction is put.
\end{abstract}

Keywords: steel anchors, pulling out, shearing, destruction of steel, concrete splitting.

Przestano do redakcji:30.05.2015

Przyjęto do druku:10.01.2016

DOI: $10.7862 / \mathrm{rb} .2015 .193$ 